\title{
Cahors « Divona » puis « Cadurci »
}

Fontaine des Chartreux

\section{(2) OpenEdition \\ Journals}

Édition électronique

URL : http://journals.openedition.org/adlfi/10454

ISSN : 2114-0502

Éditeur

Ministère de la culture

\section{Référence électronique}

"Cahors « Divona » puis « Cadurci » », ADLFI. Archéologie de la France - Informations [En ligne], Midi-

Pyrénées, mis en ligne le 01 mars 1997, consulté le 03 mai 2019. URL : http:// journals.openedition.org/adlfi/10454

Ce document a été généré automatiquement le 3 mai 2019.

(c) Ministère de la Culture et de la Communication, CNRS 


\title{
Cahors « Divona » puis « Cadurci »
}

\author{
Fontaine des Chartreux
}

Date de l'opération : 1991 (SD) ; 1990 (SD)

Inventeur(s) : Fau Laurent ; Soularyes J.-L

1 La Fontaine des Chartreux a souvent été considérée par les historiens comme étant le lieu de culte de Divona, nom éponyme de la cité à l'époque antique. Cette attribution n'était jusqu'à présent fondée que sur le caractère exceptionnel de cette résurgence de type vauclusien (eau verdoyante et limpide, débit très fluctuant) sans qu'il y eut pour autant la moindre découverte permettant de confirmer cette attribution toute conjecturale.

2 La mise au jour fortuite par le «Club spéléologique $\mathrm{H}_{2} \mathrm{O}$ » de plusieurs monnaies antiques dans le conduit immergé est à l'origine d'une série de sondages et de prospections subaquatiques.

3 En 1990, un sondage pratiqué dans le bassin de réception a permis de constater qu'à l'époque moderne d'importants travaux avaient détruit les niveaux antiques. Ces aménagements divers, liés à la présence d'un moulin qui exploitait la puissance considérable de la résurgence, devaient en effet permettre la mise en place d'un dallage, récupéré dans une église de Cahors au lendemain de la Révolution. L'importance des travaux est notable puisque ce dallage est supporté par un remblai de terre glaise de plus de 2,40 m d'épaisseur, ce qui permettait d'éviter les déperditions d'eau. Ce moulin est attesté dès le XIV ${ }^{e} s$. lorsqu'il est acquis par la Nouvelle Chartreuse, mais l'on peut penser que son origine peut remonter beaucoup plus haut dans le Moyen Âge.

4 L'année suivante une campagne de prospection et de sondage a permis d'investir la galerie noyée, lieu de découverte des premières espèces monétaires. Entraînées par le fort pendage de la galerie, c'est au total plus d'un millier de monnaies antiques qui ont pu être collectées entre $18 \mathrm{~m}$ et $31 \mathrm{~m}$ de profondeur. Ces monnaies qui s'échelonnent de la fin du I ${ }^{e r} \mathrm{~s}$. avant J.-C. jusqu'au milieu du $\mathrm{II}^{\mathrm{e}} \mathrm{s}$. après $\mathrm{J}$.-C correspondent pour les plus anciennes à des as de Nîmes et à des monnaies d'Emporion et de Tarragone.

De par leur nombre, leur usure et leur faible valeur monétaire, il est tentant de considérer ces monnaies comme étant des ex voto offerts au culte des eaux de Divona. Néanmoins, ce matériel précipité dans la galerie noyée n'est pas in situ et l'importance de ce dépôt 
cultuel est tout relatif. Nous n'avons ainsi qu'une vision tronquée qu'il sera d'ailleurs impossible de compléter compte tenu de la difficulté à envisager une opération archéologique à $100 \mathrm{~m}$ de profondeur.

6 Lors de ces plongées, d'autres objets ont été recueillis, mais ne peuvent être considérés comme votifs. Ils peuvent appartenir soit à du matériel de rebut (vaisselle et verre antique, médiéval et moderne) soit à du matériel fonctionnel (galets à encoches servant de poids de filet).

INDEX

Index chronologique : Empire romain, Moyen Âge, Temps Modernes

Index géographique : Midi-Pyrénées, Lot (46), Cahors

operation Sondage (SD) 